\title{
A sequential school based smoke prevention program in secondary school adolescents
}

\author{
A. Di Paco1, R. Boffi2, C. De Marco², N. Ambrosino1,3
}

ABSTRACT: A sequential school based smoke prevention program in secondary school adolescents. A. Di Paco, R. Boffi, C. De Marco, N. Ambrosino.

Background and Aim. The hazardous health effects of smoking and second-hand smoke are well known and have been confirmed in several studies. We wondered whether a school based programme involving media models such as those represented by famous soccer players and TV characters, was effective in prevention of smoking habit in secondary school adolescents.

Methods. Since October 2006 to May 2007 an anonymous survey was submitted to 1382 secondary schools pupils. After completing the questionnaire all students of 42 out of 70 classes selected by the school principals underwent a prevention programme consisting of 1 hour lecture on smoke healthy hazard with educational material (slides, video, leaflets). Furthermore each pupil was given card games with significant pictures. Since October 2007 to May 2008 and Since October 2008 to May 2009 pupils underwent a 1 hour interactive lesson on smoke related health hazards respectively. On December $\mathbf{2 0 0 7}$ pupils in study attended a theatre event with show business characters acting to smoke dissuasion. No intervention was performed on the 568 pupils of the other classes along all the same $\mathbf{2}$ school- year period (controls).

Results. Among other results at the end of the 2-year program $4 \%$ pupils of study group and $14 \%$ of controls reported smoking habit $(p=0.001)$ whereas $7 \%$ and $27 \%$ $(p=0.001)$ of study and control pupils respectively ignored smoking induced dependence.

Conclusion. A school based programme involving media models such as those represented by famous soccer players, TV characters, was effective in prevention of smoking habit in secondary school adolescents.

Monaldi Arch Chest Dis 2013; 79: 1, 8-11.

Keywords: Smoking habit, prevention, health education.

1 Pulmonary Rehabilitation and Weaning Center, Auxilium Vitae, Volterra

2 Tobacco Control Unit, Fondazione IRCCS, Istituto Nazionale dei Tumori, Milan,

3 Pulmonary Unit, Cardio-Thoracic Department, University Hospital Pisa, Italy.

Correspondence: Adriano Di Paco, Pulmonary Rehabilitation and Weaning Center, Auxilium Vitae, Volterra, Italy; e-mail: dipaco69@gmail.com

The hazardous health effects of smoking and second-hand smoke are well known and have been confirmed in several studies. In industrialised countries, tobacco smoke is the single most common preventable risk factor for many chronic and potentially life-threatening conditions, such as respiratory, cardiovascular and malignant disease [1-5]. The World Health Organization (WHO) has estimated that, annually, some 5 million deaths worldwide can be attributed to cigarette smoking [6]. Despite these facts, the number of smoking people, especially among children and adolescents, remains high or is even increasing in recent years in most countries [7, 8]. As the majority of smokers become addicted during adolescence, behavioural and community strategies have often aimed at preventing the initiation of smoking among children and youth $[9,10]$. Traditionally, school-based prevention programmes have been used as a way to reach as many children and adolescents as possible [11-14]. There is limited evidence that school-based programmes are effective for most tobacco use related outcomes, at least in the short term [15]. Pro-tobacco marketing and media stimulate tobacco use among youth and a ban on all tobacco promotions has been suggested with the aim to protect children [16].

We wondered whether a school based programme involving media models such as those represented by famous soccer players and TV characters, was effective in the prevention of smoking habit in secondary school (11 to 14 years old) adolescents.

Methods

Our school based programme involved 3 Phases. Survey

Since October 2006 to May 2007 a written survey was submitted to 1382 pupils of 72 first classes (10 to 12 years old) of secondary schools of Italian towns of Livorno and Pisa (Livorno, 667 54\% male, Pisa 715, 49\% male). The anonymous 21 item questionnaire explored anagraphic characteristics, personal and family smoke habit, pupils' knowledge about healthy effects of smoke. The survey is depicted in Appendix. 
Intervention (figure 1)

After completing the questionnaire all students (study group) of 42 out of 72 classes (814 pupils, 400 male) selected by the school principal, not involved in the scientific study, underwent a prevention programme consisting of a 1 hour lecture on smoke hazard supported by educational material (slides, video, leaflets). Each pupil was also given card games (UNO, Mattel, Inc. 333 Continental Boulevard El Segundo, CA 90245) modified with smoke-related significant images with the recommendation to play with parents.

Since October 2007 to May 2008 a study group underwent also a 1 hour interactive lesson on smoke related health hazards. Additional educational materials was given (card games: Memory, RobertBosch-Str 1, Ravensburg, 88188, Germany).

Furthermore on December 2007 pupils of study group also attended a theatre event with known showbusiness characters acting to smoke dissuasion. No intervention was performed on other 568 (273 male) pupils (control group) along all 2 year period.

\section{Final Survey}

On September to December 2008 the questionnaire was administered again to both groups.

\section{Statistical Analysis}

All calculations were performed with the programme 'Sigmastat release 3.5'. Data is shown as absolute numbers and percentages. The MannWhitney Rank Sum Test was used to evaluate baseline differences between study and control group. The chi-square test with Yates correction factor was used to evaluate after intervention changes in answers. A $p$ value $<0.05$ was considered as statistically significant.

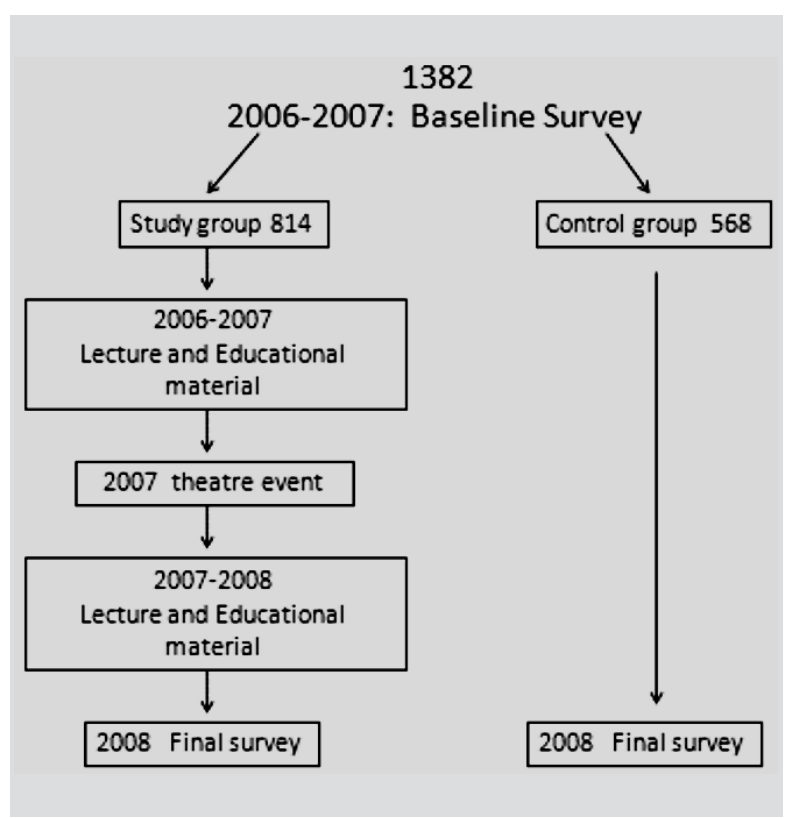

Fig. 1. - Flow chart of intervention along the 3-year period of secondary school.
Results

\section{Baseline Survey}

Study and Control Groups did not differ for sex and geographic location. As shown in table 1 only 5 out of $1382(0.4 \%)$ pupils were current smokers of at least one cigarette/day, whereas 75 $(5.4 \%)$ pupils had smoked at least one cigarette in their life, without any significant difference between study and control group.

Fifty-two \% of pupils had no smokers in their family, whereas $48 \%$ had at least one smoker, the father being the most represented $(17 \%)$, whereas $60 \%$ of pupils claimed to have at least a smoker among friends, without any significant difference between groups.

The vast majority of pupils claimed to know the potential harm of active, and passive smoke, although majority of pupils (74\%) were unaware of the chemical compound in tobacco, again without any difference between groups.

\section{Post Intervention Survey}

After intervention $4 \%$ pupils of study group were actual smokers as compared to $14 \%$ of control group $p=0.002$. Pupils smoking more than 10 cigarettes per day were by far more represented in control than in study group (11\% vs $4 \%$ respectively, Chi-square $=8.02 ; \mathrm{p}=0.0046)$.

As expected the study group reported a greater influence of school $(50 \%)$ as compared to other sources (media, parents, paper) in their education on smoke, whereas control group reported a school influence only in $19 \%$.

Intervention resulted also in: Better knowledge on second hand smoking hazard $(98 \%$ and $93 \%$ of pupils in study and control group respectively), knowledge of chemical compounds of cigarette smoke (98\% vs $92 \% \mathrm{p}=0.005)$, awareness of dependence risk of smoking habit (93\% vs $73 \%$ $\mathrm{p}=0.001$ )

\section{Discussion}

This study based on a large population shows that a school based programme involving media models, was effective in the prevention of smoking habit in secondary school adolescents. The prevalence and amount of smoking habit was significantly less, in pupils undergoing the intervention compared to control pupils. These positive results were associated with better knowledge of adverse effects of smoking habits. This study supports the effectiveness of school based programmes. Müller-Riemenschneider et al [17] evaluated the long-term effectiveness of behavioural interventions in the prevention of cigarette use among children and youth and compared the effectiveness of different school-based, community-based and multisectorial intervention strategies in adolescents up to 18 years. Differing from our study this review on a follow-up duration ranging from 12 months to 120 months, indicated that the evidence for the effectiveness of current school-based smoking prevention strategies alone was inconclu- 
Table 1. - Have you ever tried to smoke?

\begin{tabular}{lcccc}
\hline & Tot & Study & Control & p \\
\hline Never & $1302 / 1382(94.2 \%)$ & $761 / 814(93.4 \%)$ & $541 / 568(95.2)$ & ns \\
Yes and I liked it & $5 / 1382(0.4 \%)$ & $2 / 814(0.24 \%)$ & $3 / 568(0.53 \%)$ & ns \\
Yes but I didn't like & $75 / 1382(5.4 \%)$ & $51 / 814(6.3 \%)$ & $24 / 568(4.2 \%)$ & ns \\
\hline
\end{tabular}

sive and that there was more conclusive evidence for the effectiveness of community-based and multi-sectorial smoking prevention strategies [17].

To the best of our knowledge this is the first report of smoking habit in a secondary school population. Before the survey the prevalence of smoke habit in our sample of teenagers was negligible $(0.4 \%)$, increasing to $4 \%$ and $14 \%$ in study and control population respectively after 2 years. Data on smoking habit is available for Italian high school student ( $>14$ years old). Such data shows a smoke habit prevalence ranging from $9.5 \%$ to $29.5 \%$ in male students [18]. Audrey et al (19) in more than 1000012 to 13 year old adolescents, reported that a 12 month intervention was associated with a significant reduction in smoking habit prevalence in smokers $(18.8 \%$ vs $23.0 \%$ in intervention and control respectively) but not in non smokers at baseline (2.4\% vs 3.1).

On the basis of our best knowledge this is also the first report on a large adolescent population of the effectiveness of a programme based on media models like famous soccer players and TV characters. Our study indicates a significant reduction in the risk of those pupils who followed the programme becoming smokers.

This study also shows the level of knowledge of these pupils on the adverse effects of smoking habits. The lower prevalence of smoking of the subjects involved in the programme was associated with a better understanding of the harmful effects of smoking. Even though this is outside the scope of the study it is possible that the increased knowledge of the smoking damage might be involved in reducing smoking habit prevalence.

The use of characters of the popular TV shows and sports indicates the need to communicate through the media positive behaviours. Attributable risk estimates suggest that movies scenes including people smoking account for one-third to one-half of adolescent smoking onset [20-22], raising the possibility that trends in movie smoking could influence trends in adolescent smoking.

\section{Limitation of study}

The present study was neither randomised or blind. Nevertheless the choice of allocation to study or control group was performed by principals of schools, not involved in the scientific study on a classroom basis. Therefore we are confident that this choice has not influenced our results.

The study did not check for long-term effects and should also be included in the revised version of the paper.

In conclusion, a school based programme involving media models such as those represented by famous soccer players and TV characters, was effective in the prevention of smoking habit in secondary school adolescents. Whether these results can be maintained in the long term has to be evaluated.

\section{Appendix}

We propose this questionnaire to get information on your consciousness about tobacco, its use and your attitude in front of your habit to smoke. This questionnaire is anonimous and there isn't any valutation. We thank you for your collaboration.

1) $\operatorname{Sex} \mathrm{F}-\mathrm{M}$

2) Age
a) $8-10$
b) $11-13$
c) $14-16$

3) Have you ever tried to smoke?
a) never
b) yes, but I didn't like
c) yes and I liked it

4) Do you smoke?
a) yes
b) no

5) If you smoke, Who gave you your first cigarettes?

a) you took it from your parent's packet

b) a friend

c) you bought it

6) If you smoke, how many cigarettes do you smoke a day?
a) almost one
b) more than one
c) more than ten

7) If you smoke, what age did you begine?
a) $5 / 7$
b) $8 / 10$
c) $11 / 13$
d) $14 / 16$

8) In your family smokes:
a) nobody
b) my father
c) my mother
d) my brother/sister

9) Among your schoolfriends and your teachers is there anyone who smokes?
a) yes
b) no

10) In your opinion, what age is normal to begin smoking?

a) never

b) before 18

c) between 18 and 30

d) I don't know

11) As for you, why people begin to smoke? 

a) for curiosity
b) to feel adult
c) to copy our parents
d) for boredom

12) Do you believe smoking is dangerous for your health?
a) yes
b) no

13) Someone told you about the damage that provoke smoking?
a) yes
b) no

14) How did you know about the damages that smoke provokes?
a) trough TV
b) trough newspaper
c) trough school
d) trough your parents
e) trough your general practitionnaire

15) Do you believe passive smoking (that of cigarettes smoked by others) is dangerous for your health
a) yes
b) no

16) Do you believe a sportive smoker can have the same results of a non smoker?
a) yes
b) no

17) Do you know which chemical substance more known contained in tobaccos leaves?
a) cocaine
b) nicotine
c) heroine

18) Do you believe that smoking tobaccos gives a "physical dependence" as drugs
a) yes
b) no

19) Do you believe stopping smoking is:

a) very difficult

b) easy (I can stop when I want)

c) difficult but we can do it if someone helps you

d) difficult but possible if you really want it

20) Do you know is possible to receive help when you want to stop smoking?

a) yes

21) Do you think industries who produce cigarettes know well about the damage smoke provokes?
a) yes
b) no

\section{References}

1. Boffetta P, Agudo A, Ahrens W, et al. Multicenter case-control study of exposure to environmental tobacco smoke and lung cancer in Europe. J Natl Cancer Inst 1998; 90: 1440-50.

2. US Department of Health and Human Services. The health consequences of smoking: cardiovascular disease. Rockville, Maryland, USA: US Department of Health and Human Services, Office of Smoking and Health, 1983.

3. US Department of Health and Human Services. Summary of the health consequences of smoking. Chronic obstructive lung disease Report of the Surgeon General. Rockville, Maryland, USA: US Department of
Health and Human Services, Public Health Service, National Institutes of Health, National Heart, Lung and Blood Institute, 2004.

4. He J, Vupputuri S, Allen K, Prerost MR, Hughes J, Whelton PK. Passive smoking and the risk of coronary heart disease - a meta-analysis of epidemiologic studies. N Engl J Med 1999; 340: 920-6.

5. Bonita R, Duncan J, Truelsen T, Jackson RT, Beaglehole R. Passive smoking as well as active smoking increases the risk of acute stroke. Tob Control 1999; 8: 156-60.

6. Ezzati M, Lopez AD. Estimates of global mortality attributable to smoking in 2000. Lancet 2003; 362: 847-52.

7. Warren CW, Jones NR, Peruga A, et al. Global youth tobacco surveillance, 2000- 2007. MMWR Surveill 2008; 57: 1-28.

8. Bundeszentrale fur̈ Gesundheitliche Aufkla"rung. Neue Ergebnisse zur Entwicklung des Rauchverhaltens von Jugendlichen (change in smoking rates among adolescents in Germany). http://www.bzga.de/stadien (accessed 12 June 2008).

9. Lantz PM, Jacobson PD, Warner KE, et al. Investing in youth tobacco control: a review of smoking prevention and control strategies. Tob Control 2000; 9: 47-63.

10. Thomas M. In: Walker A, ed. Living in Britain: Results from the 1996 General Household Survey. London, UK: The Stationary Office, 1998.

11. Fletcher A, Bonell C, Hargreaves J. School effects on young people's drug use: a systematic review of intervention and observational studies. $J$ Adolesc Health 2008; 42: 209-20.

12. Brinn MP, Carson KV, Esterman A, Chang AB, Smith BJ. Mass media interventions for preventing smoking in young people. Cochrane Database Syst Rev 2010; 11: CD001006.

13. Cahill K, Perera R. Quit and Win contests for smoking cessation. Cochrane Database Syst Rev 2008; 4: CD004986.

14. Cahill K, Perera R. Competitions and incentives for smoking cessation. Cochrane Database Syst Rev 2011; 4: CD004307.

15. Carson KV, Brinn MP, Labiszewski NA, Esterman AJ, Chang AB, Smith BJ. Community interventions for preventing smoking in young people. Cochrane Database Syst Rev 2011; 7: CD001291.

16. Sabiston CM, Lovato CY, Ahmed R, et al. School smoking policy characteristics and individual perceptions of the school tobacco context: are they linked to students' smoking status? J Youth Adolesc 2009; 38: 1374-87.

17. Muller-Riemenschneider F, Bockelbrink A, Reinhold T, Rasch A, Greiner W, Willich SN. Long-term effectiveness of behavioural interventions to prevent smoking among children and youth. Tob Control 2008; 17: 301-312.

18. Gallus S, Muttarak R, Martínez-Sánchez JM, Zuccaro P, Colombo P, La Vecchia C. Smoking prevalence and smoking attributable mortality in Italy, 2010. Prev Med 2011; 52: 434-8.

19. Audrey S, Holliday J, Campbell R. It's good to talk: adolescent perspectives of an informal, peer-led intervention to reduce smoking. Social Sci Med 2006; 63: 320-34.

20. Dalton MA, Sargent JD, Beach ML, et al. Effect of viewing smoking in movies on adolescent smoking initiation: a cohort study. Lancet 2003; 362 (9380): 281-285.

21. Titus-Ernstoff L, Dalton MA, Adachi-Mejia AM, Longacre MR, Beach ML. Longitudinal study of viewing smoking in movies and initiation of smoking by children. Pediatrics 2008; 121: 15-21.

22. Wellman RJ, Sugarman DB, DiFranza JR, Winickoff JP. The extent to which tobacco marketing and tobacco use in films contribute to children's use of tobacco. A Metaanalysis. Arch Pediatr Adolesc Med 2006; 160: 1285-1296. 